\title{
Ni@RuM (M=Ni or Co) core@shell nanocrystals with high mass activity for overall water-splitting catalysis
}

\author{
Shan Zhang ${ }^{1,2,3 \dagger}$, Fan $\mathrm{Lv}^{3 \dagger}$, Xiaoyan Zhang ${ }^{1,2,3}$, Yelong Zhang ${ }^{3}$, Haishuang Zhu ${ }^{1,2}$, Huanhuan Xing ${ }^{1,2}$, \\ Zijie $\mathrm{Mu}^{3}$, Jing $\mathrm{Li}^{1,2^{*}}$, Shaojun $\mathrm{Guo}^{3^{*}}$ and Erkang Wang ${ }^{1,2}$
}

\begin{abstract}
Developing efficient water-splitting electrocatalysts with high mass activity is in urgent need for largescale sustainable production of hydrogen but, still remains as a big challenge. Herein, we report a one-pot method to fabricate a series of core@shell Ni@RuM ( $\mathrm{M}=\mathrm{Ni}$ or $\mathrm{Co})$ nanocrystals (NCs) with $\mathrm{Ni}$ as the core and tunable $\mathrm{RuM}(\mathrm{M}=\mathrm{Ni}$ or $\mathrm{Co})$ as the alloy shell for efficient water-splitting catalysis. Among these core@shell NCs, the obtained Ni@RuNi NCs exhibit the highest intrinsic activity for hydrogen evolution reaction (HER) and possess an outstanding mass activity of $1590 \mathrm{~mA} \mathrm{mg}_{\mathrm{Ru}}^{-1}$ at $0.07 \mathrm{~V}$ vs. reversible hydrogen electrode (RHE), which is 1.7 times higher than that of commercial $\mathrm{Pt} / \mathrm{C}$ $\left(950 \mathrm{~mA} \mathrm{mg}_{\mathrm{Pt}}{ }^{-1}\right)$. As for oxygen evolution reaction (OER), the prepared $\mathrm{Ni} @ \mathrm{Ru}_{0.4} \mathrm{Co}_{0.6} \mathrm{NCs}$ with optimized shell composition achieve more enhanced mass activity of $270 \mathrm{~mA} \mathrm{mg}_{\mathrm{Ru}}{ }^{-1}$ at $1.56 \mathrm{~V} v s$. RHE, approaching three times higher than that of commercial $\mathrm{RuO}_{2}\left(89 \mathrm{~mA} \mathrm{mg}_{\mathrm{Ru}}{ }^{-1}\right)$. The superb mass activity of these Ni@RuM (M=Ni or Co) NCs can be attributed to their core@shell structure and modulated electronic structure through alloying with $\mathrm{Ni}$ or Co metal in the shell.
\end{abstract}

Keywords: electrocatalysis, ruthenium, core-shell, oxygen evolution reaction, hydrogen evolution reaction

\section{INTRODUCTION}

Electrochemical water splitting is considered as the key technology to provide high-purity hydrogen for the nextgeneration of sustainable global energy system [1-3]. The key to the development of this technique is the exploitation of effective catalysts to improve the slow kinetics of both hydrogen evolution reaction (HER) and oxygen evolution reaction (OER), thus maximizing the utilization efficiency of electricity [4-7]. Although some progress has been made in respect of non-noble metal catalysts, $\mathrm{Pt} / \mathrm{C}$ and $\mathrm{RuO}_{2} / \mathrm{IrO}_{2}$ still outperform most of the reported catalysts for HER and OER, respectively [8-14]. And their wide application is severely hindered by their natural scarcity and high cost [15]. Therefore, how to further improve their catalytic activity, especially the mass activity, is an urgent task.

Compared with $\mathrm{Pt}$ and $\mathrm{Ir}, \mathrm{Ru}$ is much cheaper [16]. Meanwhile, besides water oxidation catalysis, recently $\mathrm{Ru}$ based materials have also been proved to be good candidates for HER with small overpotential and Tafel slope [17-21]. However, their mass activities are still far from satisfactory, preventing their further application [22-24]. The way to enhance the mass activity is optimization of both intrinsic activity and the number of active sites on the surface. From this point of view, the core@shell nanocatalysts with a core of cheap transition metal (such as $\mathrm{Ni}$ ) surrounded by a thin layer of noble metal as the shell are favorable to realize the above proposals. With such core@shell structure, it can not only maximize the utilization of noble metal, but also regulate the intrinsic activity of the exposed shell by the core induced strain/ electronic effect [25-27] or further modulate the shell composition [28-30]. This kind of core@shell structure design has been well developed and becomes a research hotspot in the Pt-based oxygen reduction catalysts [3134], while few Ru-based core@shell electrocatalysts, especially with high mass activity, have been reported.

In this work, we report a new method to synthesize

\footnotetext{
${ }^{1}$ State Key Laboratory of Electroanalytical Chemistry, Changchun Institute of Applied Chemistry, Chinese Academy of Sciences, Changchun 130022, China

${ }^{2}$ University of Science and Technology of China, Hefei 230029, China

${ }^{3}$ Department of Materials Science \& Engineering, College of Engineering, Peking University, Beijing 100871, China

These authors contributed equally to this study.

* Corresponding authors (emails: lijingce@ciac.ac.cn (Li J); guosj@pku.edu.cn (Guo S))
} 
core@shell Ni@RuM ( $\mathrm{M}=\mathrm{Ni}$ or $\mathrm{Co})$ nanocrystals (NCs) featured with $\mathrm{Ni}$ as a core and tunable thin Ru-based alloy layer as a class of highly efficient electrocatalysts with high mass activity for HER and OER. Specifically, the core@shell Ni@RuNi NCs display the highest HER specific activity of $12 \mathrm{~mA} \mathrm{~cm}_{\mathrm{ECSA}}{ }^{-2}$ (ECSA means electrochemically active surface area) at an overpotential of $0.07 \mathrm{~V} v s$. reversible hydrogen electrode (RHE), and yield a high mass activity of $1590 \mathrm{~mA} \mathrm{mg}_{\mathrm{Ru}}{ }^{-1}$, almost double the value of commercial $\mathrm{Pt} / \mathrm{C}\left(950 \mathrm{~mA} \mathrm{mg} \mathrm{Pt}_{\mathrm{Pt}}{ }^{-1}\right)$. As for OER, the core@shell Ni@ $\mathrm{Ru}_{0.4} \mathrm{Co}_{0.6} \mathrm{NCs}$ exhibit the current density of $2.24 \mathrm{~mA} \mathrm{~cm}_{\text {geo }}{ }^{-2}$ (geo represents geometric area) at $1.56 \mathrm{~V}$ vs. RHE with a very low mass loading of $2 \mu \mathrm{g}_{\mathrm{Ru}} \mathrm{cm}_{\text {geo }}{ }^{-2}$, six times higher than that of commercial $\mathrm{RuO}_{2}\left(0.36 \mathrm{~mA} \mathrm{~cm}_{\text {geo }}{ }^{-2}\right)$. The greatly enhanced mass activities for HER and OER of these core@shell Ru-based NCs are due to the shell-induced electronic effect through alloying $\mathrm{Ru}$ with $\mathrm{Ni}$ or $\mathrm{Co}$ on the surface, which enhances the $\mathrm{Ru}$ atom exposure and meantime boosts the intrinsic activity.

\section{EXPERIMENTAL SECTION}

\section{Reagents}

Ruthenium(III) acetylacetonate $\left(\mathrm{Ru}(\mathrm{acac})_{3}\right)$ was obtained from Alfa Aesar. Nickel(II) acetylacetonate $\left(\mathrm{Ni}(\mathrm{acac})_{2}\right)$ and cobalt(II) acetylacetonate $\left(\mathrm{Co}(\mathrm{acac})_{2}\right)$ were purchased from Sinopharm Chemical Regent Co., Ltd. Oleylamine (OAm) was bought from Sigma-Aldrich. Hexadecylammonium chloride (CTAC) was taken from Beijing Bai Ling Wei Technology Co., Ltd. The commercial Pt/C (20 wt\%) was obtained from Johnson-Matthey company. The ruthenium(IV) oxide $\left(\mathrm{RuO}_{2}\right)$ was bought from Sigma-Aldrich. All chemicals were used as received and water was purified by a Millipore system.

\section{Synthesis of Ni@RuNi NCs}

In a typical process, $\mathrm{Ru}(\mathrm{acac})_{3}(8 \mathrm{mg}), \mathrm{Ni}(\mathrm{acac})_{2}(5 \mathrm{mg})$ and CTAC $(20 \mathrm{mg})$ were mixed with $5 \mathrm{~mL}$ OAm into a vial and then ultrasonicated for $30 \mathrm{~min}$. The homogeneous solution was heated to $250^{\circ} \mathrm{C}$ and kept for $3 \mathrm{~h}$ in oil bath. Thereafter, the mixture was cooled down to room temperature naturally and the products were centrifuged by cyclohexane. Finally, the resultants were washed three times by cyclohexane, then dispersed in cyclohexane for further use. $\mathrm{Ni} @ \mathrm{Ru}_{x} \mathrm{Co}_{y} \mathrm{NCs}$ with different feeding ratios were prepared by similar procedure.

\section{Characterizations}

Transmission electron microscopy (TEM) and high-re- solution TEM (HRTEM) measurements were conducted on a Tecani-G2 T20 and F20 operated at $200 \mathrm{kV}$. Powder $\mathrm{X}$-ray diffraction (XRD) spectra were collected on a X'Pert-Pro MPD diffractometer (Netherlands PAN analytical) with $\mathrm{Cu} \mathrm{Ka} \mathrm{X}$-ray radiation. The X-ray photoelectron spectroscopy (XPS) profiles were taken on an ESCALAB-MKII 250 photoelectron spectrometer (VG Co. UK) with $\mathrm{Al} \mathrm{Ka}$ radiation. The concentrations of catalysts ink were determined by inductively coupled plasma-atomic emission spectrometry (ICP-AES).

\section{Electrochemical measurements}

Electrochemical tests were carried out on an electrochemical workstation (CHI660E, Shanghai, China) based on a classical three-electrode system. The $\mathrm{Ag} / \mathrm{AgCl}$ electrode and a graphite rod were used as the reference electrode and the counter electrode, respectively. The glassy carbon (GC, $5 \mathrm{~mm}$ ) disk electrode loaded with the catalysts ink was applied as the working electrode. The catalysts ink $\left(1 \mathrm{mg} \mathrm{mL}^{-1}\right)$ was prepared by sonicating the mixture of catalyst, $\mathrm{H}_{2} \mathrm{O}$, isopropanol and $5 \mathrm{wt} \%$ Nafion (volume ratio=3:1:0.08) until a homogeneous dispersion was obtained. Then, $10 \mu \mathrm{L}$ of the ink was dropped on the GC electrode and dried at room temperature naturally. The loading amount was about $0.4 \mu \mathrm{g}_{\mathrm{Ru}}$ for each catalyst, which was determined by ICP-AES. The commercial Pt/C and $\mathrm{RuO}_{2}$ with similar loadings as $\mathrm{Ni@RuNi} \mathrm{NCs}$ and $\mathrm{Ni} @ \mathrm{Ru}_{0.4} \mathrm{Co}_{0.6} \mathrm{NCs}$ were also measured for better comparison, respectively. HER and OER of various catalysts were conducted in nitrogen and oxygen-saturated $0.1 \mathrm{~mol} \mathrm{~L}^{-1} \mathrm{KOH}$ electrolyte with the scan rate of $5 \mathrm{mV} \mathrm{s}^{-1}$, respectively. For stability test, the catalysts ink was deposited on the carbon fiber paper, and then dried naturally to carry out the chronopotentiometry measurement. To determine the ECSA of catalysts, the copper underpotential deposition $\left(\mathrm{Cu}_{\text {upd }}\right)$ method was utilized, which has been widely applied to measure the ECSA of $\mathrm{Ru}$-based catalysts. Specifically, cyclic voltammetry (CV) was performed in nitrogen-saturated $0.25 \mathrm{~mol} \mathrm{~L}^{-1} \mathrm{H}_{2} \mathrm{SO}_{4}$ and $0.25 \mathrm{~mol} \mathrm{~L}^{-1} \mathrm{H}_{2} \mathrm{SO}_{4}+10 \mathrm{mmol} \mathrm{L}^{-1} \mathrm{CuSO}_{4}$ with potential range between 0.3 and $0.7 \mathrm{~V} v s$. RHE. Therefore, the $\mathrm{Cu}_{\mathrm{upd}}$ stripping charge $\left(Q_{\mathrm{Cu}}\right)$ associated with active $\mathrm{Ru}$ sites could be obtained by integrating the close part of two curves. Provided that $420 \mu \mathrm{C} \mathrm{cm}^{-2}$ was needed to form saturated $\mathrm{Cu}_{\text {upd }}$ monolayer on active sites, then the ECSA could be calculated as follow:

$\operatorname{ECSA}_{\left(\mathrm{cm}^{2}\right)}=\frac{Q_{\mathrm{Cu}}}{M_{\text {metal }} \times 420 \mu \mathrm{C} \mathrm{cm}^{-2}}$,

where $M_{\text {metal }}$ was mass of metal loaded on the working electrode. 


\section{RESULTS AND DISCUSSION}

The core@shell Ni@RuNi NCs were prepared by a simple colloidal-chemical approach, using $\mathrm{Ru}(\mathrm{acac})_{3}$ and $\mathrm{Ni}(\mathrm{acac})_{2}$ as the metal precursors, OAm and CTAC as the solvent and surfactant, respectively (details in the experimental section). The morphology of the Ni@RuNi NCs was firstly characterized by TEM, in which they were relatively regular polyhedron with an average size of $20 \mathrm{~nm}$ (Fig. 1a and Fig. S1). Powder XRD (PXRD) measurement verifies the co-existence of $\mathrm{Ru}$ and $\mathrm{Ni}$ crystalline phase in the Ni@RuNi NCs (Fig. 1b).
The strong peaks of $44.6^{\circ}$ and $51.9^{\circ}$ match well with the (111) and (200) plane of Ni phase (JCPDS No. 70-0989), respectively, while the weak peak of $41.5^{\circ}$ is located between the aforementioned Ni phase and Ru phase (JCPDS No. 88-2333), indicating the existence of RuNi alloy. TEM energy dispersive X-ray spectroscopy (EDS) element mapping (Fig. 1c) and line-scanning (Fig. 1d) show that the prepared Ni@RuNi NCs have a Ni core and Rurich shell with obviously disparate element distribution, further indicating the core@shell structure of Ni@RuNi NCs. Two enlarged HRTEM images (Fig. 1e) display clear

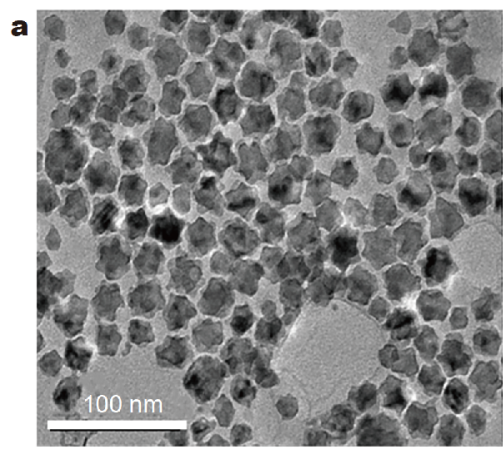

b
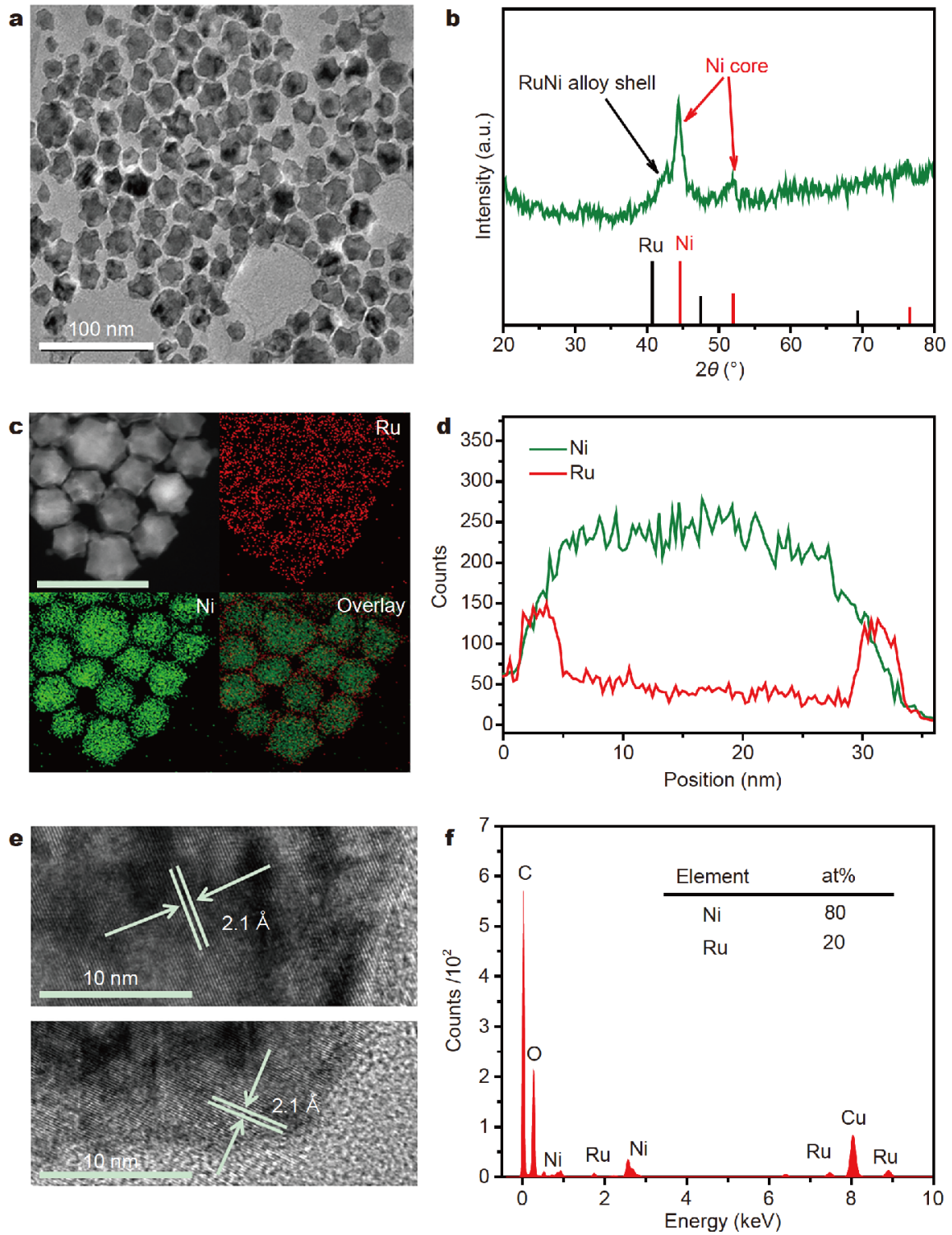

Figure 1 (a) TEM image and (b) XRD pattern of the obtained Ni@RuNi NCs. (c) The high-angle annular dark field-scanning TEM (HAADF-STEM) element mapping and (d) the corresponding EDS line scan profile of the prepared Ni@RuNi NCs. (e) HRTEM image and (f) EDS profile of the synthesized Ni@RuNi NCs. 
lattice distance of $2.1 \AA$ in the center and edge region of the obtained Ni@RuNi NCs, respectively. This lattice distance is between that of the (111) plane of Ru phase $(2.2 \AA)$ and $\mathrm{Ni}$ phase $(2.0 \AA)$, another evidence of the formation of RuNi alloy on the surface. Additionally, the atomic ratio of $\mathrm{Ru}: \mathrm{Ni}$ is about $2: 8$ according to the result of EDS spectrum (Fig. 1f).

Furthermore, the resultant shell composition of the synthesized Ni@RuNi NCs above can be altered from RuNi to RuCo alloys simply by adding a specific amount of $\mathrm{Co}(\mathrm{acac})_{2}$ as Co source into the reaction system. A

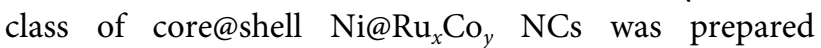
through a similar procedure with various molar ratios (Figs S2 and S3). When the feeding molar ratio of Co and $\mathrm{Ni}$ source was 3:1, the core@shell $\mathrm{Ni} @ \mathrm{Ru}_{0.4} \mathrm{Co}_{0.6} \mathrm{NCs}$ were obtained. The typical morphology of $\mathrm{Ni} @ \mathrm{Ru}_{0.4} \mathrm{Co}_{0.6} \mathrm{NCs}$ is shown in Fig. 2a and Fig. S4. The corresponding HRTEM image (Fig. 2b) reveals the clear crystal lattice with $d$-spacing of $2.1 \AA$, which is between those of the
(111) plane of Ru phase $(2.2 \AA)$, Ni phase $(2.0 \AA)$ and Co phase (2.0 ̊, JCPDS No. 88-2325). This explains the Ru

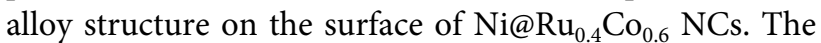

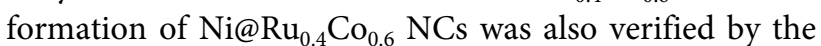
PXRD pattern (Fig. 2c, up), in which the peak of $44.6^{\circ}$ is indexed to (111) plane of the Ni phase (JCPDS No. 700989), and the shoulder peak around $43^{\circ}$ lies between the (111) planes of the Ru phase (JCPDS No. 88-2333) and $\mathrm{Ni} / \mathrm{Co}$ phase. These imply that Ru-based alloy was formed during the reaction process. By the way, the real atomic ratio of Ru:Ni:Co is 2:7:3 based on the EDS profile (Fig. 2c, down). To further analyze the composition of the alloy shell, the EDS element line-scanning (Fig. 2d) was carried out. It reveals that the shell consists of RuCo alloy with $\mathrm{Ni}$ as a core, re-confirming the core@shell $\mathrm{Ni} @ \mathrm{Ru}_{0.4} \mathrm{Co}_{0.6}$ structure. In order to further confirm the formation of the alloy shell, the etching of Ni core was carried out by $\mathrm{Fe}^{3+}$, as illustrated by the TEM image (Fig. S5a, S5c), and then characterized by XRD. The peak
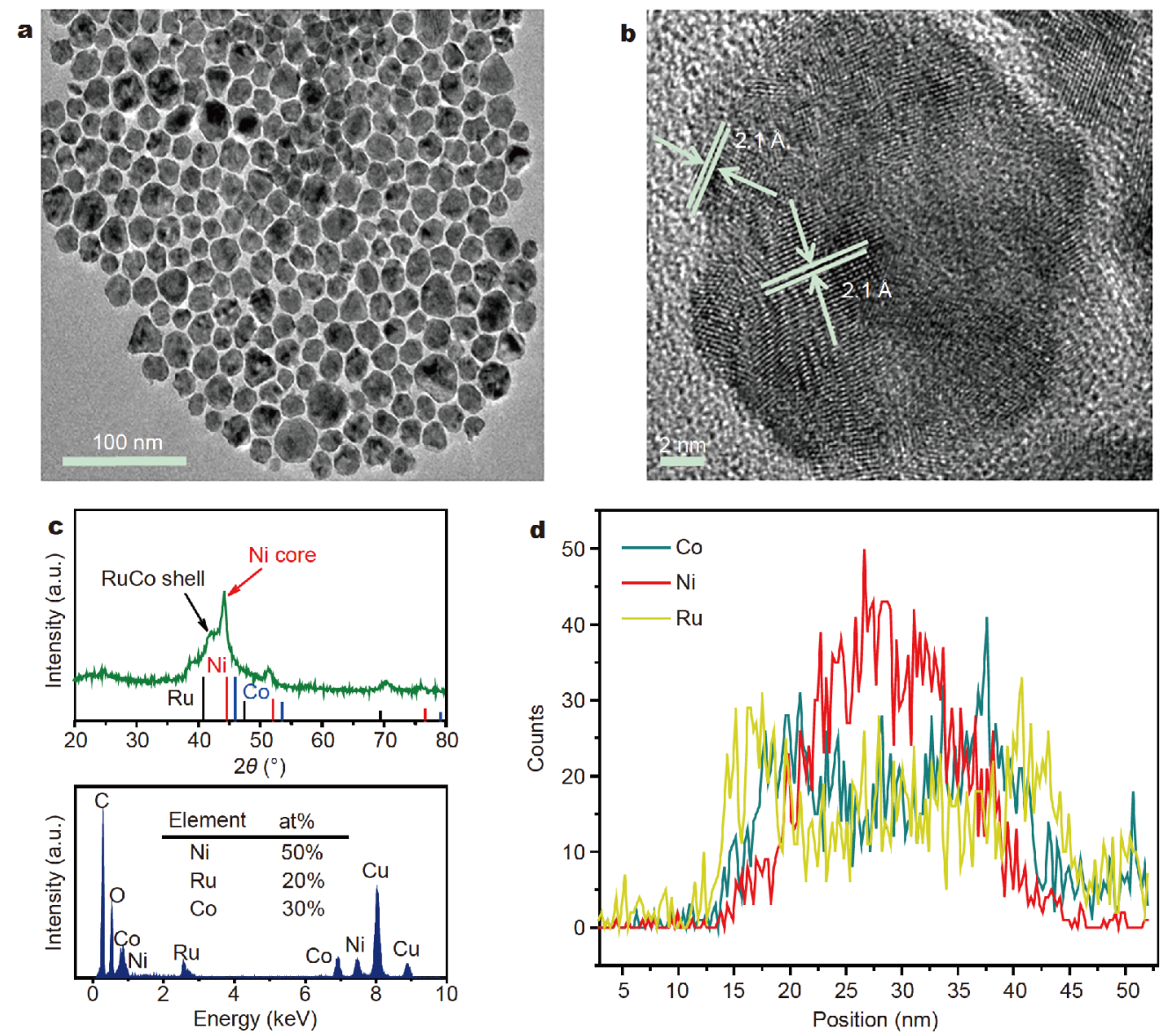

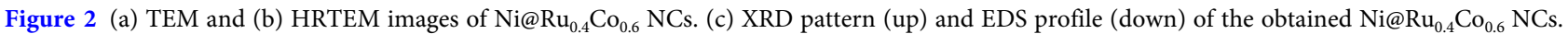
(d) The EDS line scan profile of $\mathrm{Ni@} \mathrm{Ru}_{0.4} \mathrm{Co}_{0.6} \mathrm{NCs}$. 
of Ni core disappears, and only one diffraction peak assigned to alloy can be observed in the XRD pattern, which is a strong evidence for the formation of the alloy shell (Fig. S5b, S5d).

Moreover, the surface chemical states of the Ni@ $\mathrm{Ru}_{0.4} \mathrm{Co}_{0.6} \mathrm{NCs}$ and $\mathrm{Ni} @ \mathrm{RuNi} \mathrm{NCs}$ were studied by XPS, (Fig. 3). In Ru 3p spectrum (Fig. 3a), two pairs of adjacent peaks centered at 462 and $484 \mathrm{eV}$ are attributed to $\mathrm{Ru} 3 \mathrm{p}_{3 / 2}$ and $3 \mathrm{p}_{1 / 2}$ of metallic $\mathrm{Ru}(0)$ and $\mathrm{Ru}^{4+}$, respectively $[22,35]$. Compared with the commercial $\mathrm{Ru} / \mathrm{C}$ (as reference), the $\mathrm{Ru}(0)$ peak of $\mathrm{Ni@RuNi} \mathrm{NCs}$ and $\mathrm{Ni} @ \mathrm{Ru}_{0.4} \mathrm{Co}_{0.6} \mathrm{NCs}$ all exhibit positive shifts, which is attributed to modified electron structure of $\mathrm{Ru}$ in these core-shell alloy NCs owing to the ligand or strain effect $[19,36]$. In this way, the hydrogen binding energy on $\mathrm{Ru}$ sites might be weakened because of the presence of higher valence states for $\mathrm{Ru}$ sites in $\mathrm{Ni@RuNi} \mathrm{NCs,} \mathrm{which} \mathrm{is}$ beneficial to its HER activity [37]. In addition, we also

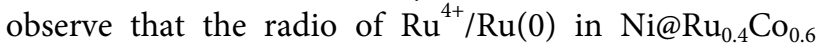
NCs (0.57) is much larger than in Ni@RuNi NCs (0.48), and the higher ratio of $\mathrm{Ru}^{4+} / \mathrm{Ru}(0)$ is favorable for OER process. By the way, the XPS spectra of both Ni $2 p$ (Fig. 3b) and Co 2p (Fig. 3c) also confirm their existence in the corresponding products.

Before the electrochemical measurement, in order to ensure the cleanness of our synthesized Ru-based NCs' surface, the resulting NCs were first deposited onto carbon black by sonication, and then treated with acetic acid to remove the residual OAm. Thereafter, the ECSA of these Ni@RuM ( $\mathrm{M}=\mathrm{Ni}$ or $\mathrm{Co})$ catalysts were firstly tested by a well-established $\mathrm{Cu}_{\text {upd }}$ method, which had been applied for Ru-based catalysts successfully before [32]. The prepared catalyst ink was dropped onto the GC electrode $\left(0.196 \mathrm{~cm}^{2}\right)$ and dried naturally to conduct the $\mathrm{CV}$ test (Fig. S6). The anodic peak near $0.4 \mathrm{~V} v s$. RHE was associated with the strip of deposited $\mathrm{Cu}$, which matched well with previous reports [33,34]. According to the $\mathrm{Cu}$ stripping charge $\left(Q_{\mathrm{Cu}}\right)$ and the charge needed for the formation of saturated $\mathrm{Cu}_{\text {upd }}$ monolayer $\left(420 \mu \mathrm{C} \mathrm{cm}^{-2}\right)$, the ECSAs of Ru-based catalysts that we prepared were obtained and summarized in Table S1. Then the HER specific activity normalized by ECSA of the as-prepared core@shell Ni@RuM ( $\mathrm{M}=\mathrm{Ni}$ or $\mathrm{Co})$ catalysts in $0.1 \mathrm{~mol} \mathrm{~L}^{-1} \mathrm{KOH}$ was examined. As shown in Fig. 4a, the specific activity of the various $\mathrm{Ru}$-based catalysts follows the order of $\mathrm{Ni@RuNi} \mathrm{NCs}>\mathrm{Ni} @ \mathrm{Ru}_{0.6} \mathrm{Co}_{0.4} \mathrm{NCs} \approx$

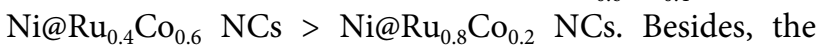
best-performing Ni@RuNi NCs exhibit better specific activity than commercial Pt/C (Fig. S7). To provide more intuitive comparison, the histogram of specific activity of various catalysts at the overpotential of $70 \mathrm{mV} v s$. RHE is given in Fig. 4b. Obviously, the core@shell Ni@RuNi NCs display the outstanding specific activity of $11.96 \mathrm{~mA} \mathrm{~cm}^{-2}$, which is higher than those of other core@shell Ru-based NCs catalysts under the same condition. In order to further reflect the advantage of $\mathrm{Ni@RuNi} \mathrm{NCs}$ as HER catalysts in basic media. We compare the polarization curves of the core@shell $\mathrm{Ni@RuNi} \mathrm{NCs}$ and the commercial Pt/C normalized by the geometric area with a very low loading mass $\left(2 \mu \mathrm{g}_{\mathrm{Ru} \text { or } \mathrm{Pt}} \mathrm{cm}^{-2}\right)$. The obtained Ni@RuNi NCs exhibit better performance than the commercial $\mathrm{Pt} / \mathrm{C}$ in such case (Fig. 4c). As shown in Fig. 4d, the mass activity of $\mathrm{Ni@RuNi} \mathrm{NCs} \mathrm{is} 1590 \mathrm{~mA} \mathrm{mg}_{\mathrm{Ru}}{ }^{-1}$, which is 1.7 times as much as that of commercial $\mathrm{Pt} / \mathrm{C}\left(950 \mathrm{~mA} \mathrm{mg}_{\mathrm{Pt}}{ }^{-1}\right)$ at the overpotential of $70 \mathrm{mV} v s$. RHE, representing the best level of other Ru-based catalysts reported yet (Table S2). The mass activity of the Ni@RuNi NCs for HER is ascribed to the favorable core@shell structure. The thin $\mathrm{RuNi}$ alloy layer not only reduces the usage of $\mathrm{Ru}$, but also modulates the electronic structure, which is beneficial to the HER eletrocatalysis $[19,38,39]$.
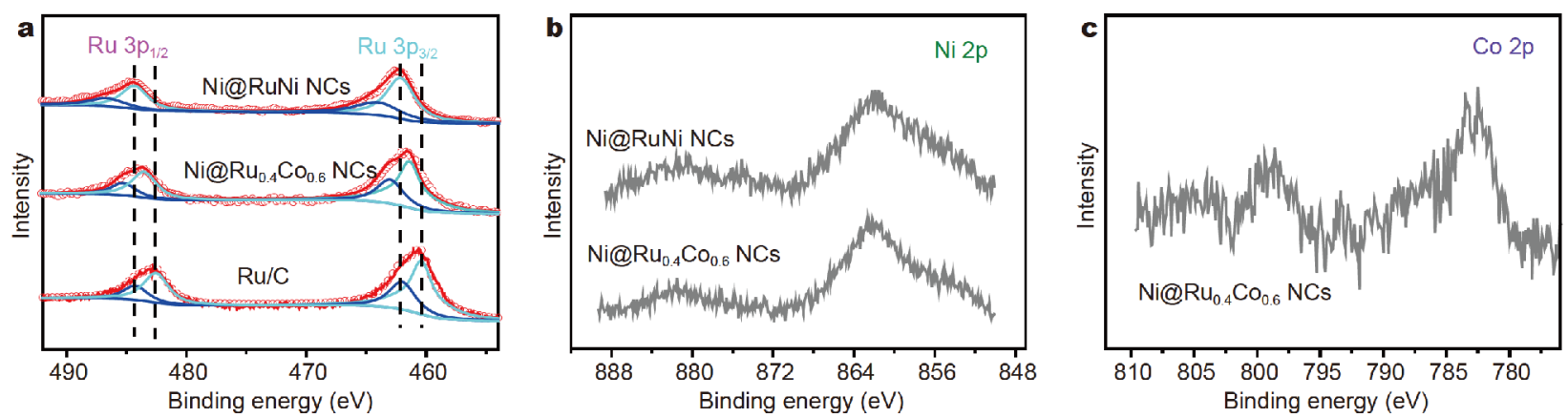

Figure 3 XPS spectra of (a) Ru of the obtained Ni@RuNi NCs, Ni@Ru ${ }_{0.4} \mathrm{Co}_{0.6} \mathrm{NCs}$ and commercial Ru/C. (b) The XPS spectra of Ni of the resulting

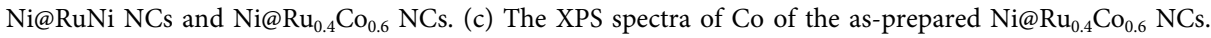



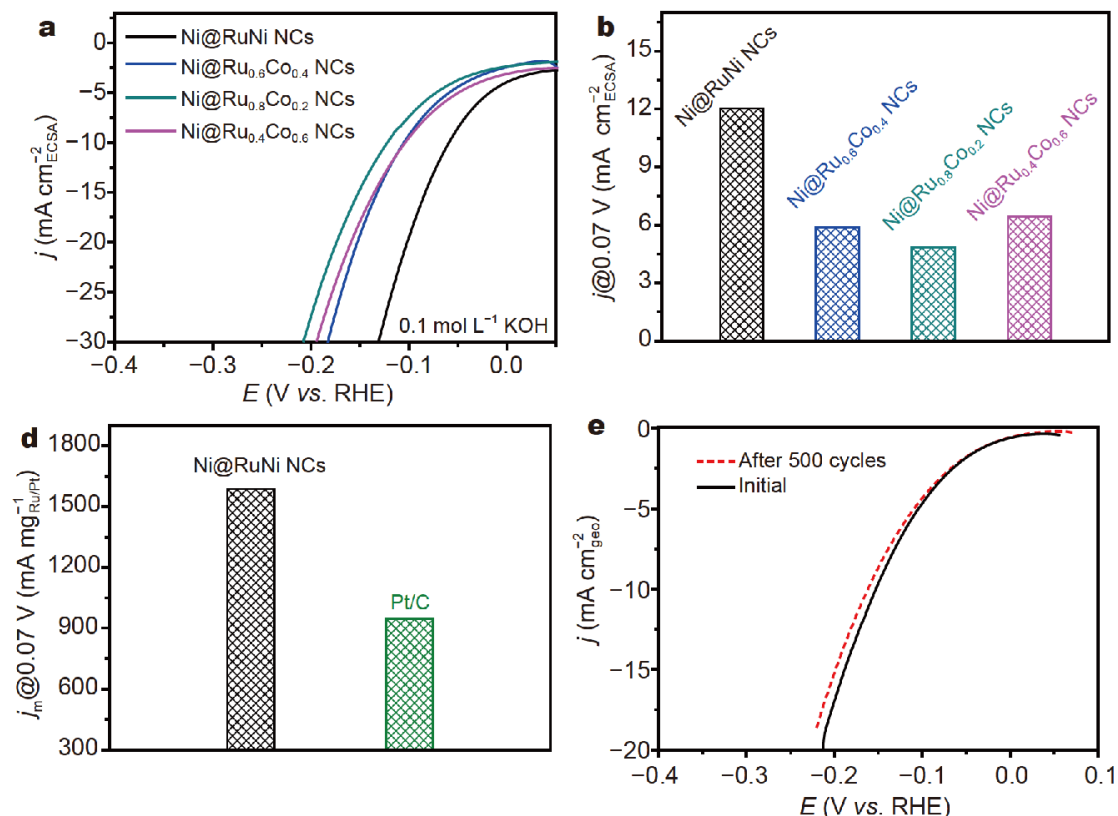
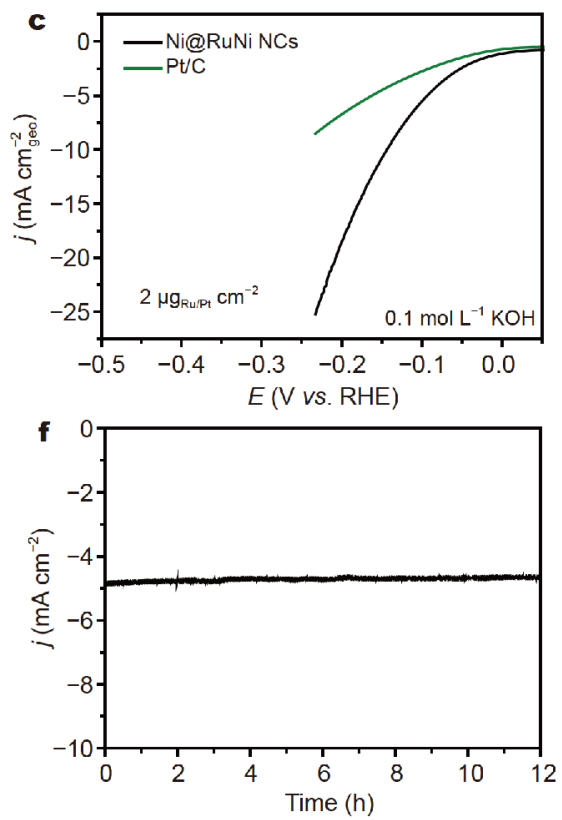

Figure 4 (a) The specific activity for HER normalized by ECSA in $0.1 \mathrm{~mol} \mathrm{~L}^{-1} \mathrm{KOH}$. (b) The current density of various catalysts normalized by ECSA at the overpotential of $70 \mathrm{mV} v s$. RHE. (c) Polarization curves of Ni@RuNi NCs and commercial Pt/C normalized by geometric area at low loading mass. (d) The corresponding mass activity of Ni@RuNi NCs and commercial Pt/C at the overpotential of $70 \mathrm{mV} v s$. RHE. (e) Polarization curves of Ni@RuNi NCs before and after 500 CV cycles. (f) Chronoamperometric measurement of the obtained Ni@RuNi NCs.

Furthermore, the stability of the Ni@RuNi NCs was checked by accelerated durability test (ADT) and chronoamperometry measurement. Fig. 4e displays the polarization curves of the Ni@RuNi NCs before and after $500 \mathrm{CV}$ cycles. The ADTs only lead to an increase of $8 \mathrm{mV}$ in $\eta_{10}$, implying the excellent durability of the Ni@RuNi NCs. In chronoamperometry measurement, the $\mathrm{Ni@RuNi}$ NCs can maintain constant current density for $12 \mathrm{~h}$ (Fig. 4f). In addition, no aggregation is observed for Ni@RuNi NCs (Fig. S8), revealing they are still dispersible after the stability test. The faradaic efficiency of Ni@RuNi NCs for HER is calculated to be $96 \%$ (Fig. S9), reflecting that $\mathrm{H}_{2}$ production plays a dominant role in the electron transfer process.

Besides the excellent HER catalytic performance, the $\mathrm{Ni} @ \mathrm{RuM}(\mathrm{M}=\mathrm{Ni}$ or $\mathrm{Co}) \mathrm{NCs}$ also display high specific activity and stability for OER in $0.1 \mathrm{~mol} \mathrm{~L}^{-1} \mathrm{KOH}$. Fig. 5a shows the specific activity of our Ru-based NCs catalysts

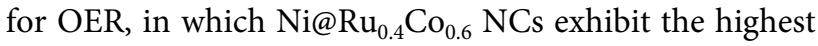
specific activity. At the overpotential of $330 \mathrm{mV} v s$. RHE,

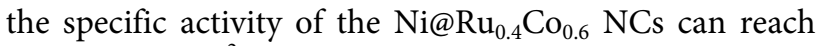
$4.3 \mathrm{~mA} \mathrm{~cm}_{\mathrm{ECSA}}{ }^{-2}$, which is two or three times larger than other samples (Fig. 5b). Fig. $5 \mathrm{c}$ presents the polarization

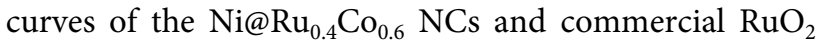
normalized by the geometric area. The obtained $\mathrm{Ni} @ \mathrm{Ru}_{0.4} \mathrm{Co}_{0.6} \mathrm{NCs}$ exceed the commercial $\mathrm{RuO}_{2}$ with the same low loading mass of $4 \mu \mathrm{g}_{\mathrm{Ru}} \mathrm{cm}^{-2}$. Furthermore, their mass activity was calculated (Fig. 5d) based on the results of ICP-AES and the polarization curves. As is shown, the

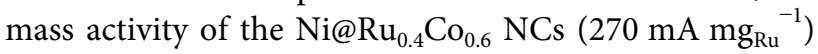
is three times as much as that of commercial $\mathrm{RuO}_{2}$ $\left(89 \mathrm{~mA} \mathrm{mg}_{\mathrm{Ru}}{ }^{-1}\right)$. The unique $\mathrm{Ni} @ \mathrm{Ru}_{0.4} \mathrm{Co}_{0.6}$ structure may be responsible for the high mass activity and the oxidation of $\mathrm{Ru}$ can be promoted by alloying with $\mathrm{Co}$, as confirmed by XPS, thus boosting the OER performance. Table S3 in the Supplementary information summarizes the mass activity of some reported Ru-based catalysts for OER for better comparison. To evaluate the stability of the Ni@ $\mathrm{Ru}_{0.4} \mathrm{Co}_{0.6} \mathrm{NCs}$, the ADTs were carried out over the potential window from 1.3 to $1.5 \mathrm{~V} v s$. RHE for 500 cycles. The catalytic performance does not show obvious decay after ADTs (Fig. 5e), suggesting the superior dur-

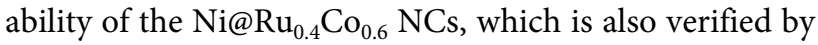
the chronoamperometry measurement (Fig. 5f). Similarly,

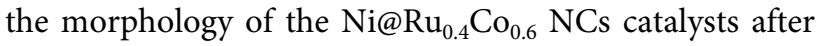
the OER stability test was characterized by TEM (Fig. S10). They keep good dispersibility during the

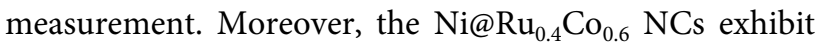
Faradaic efficiency of $92 \%$ (Fig. S11), which means $\mathrm{O}_{2}$ is the main product during the electrocatalysis. In addition, the stability of the other three kinds of Ru-based catalysts including $\mathrm{Ni@RuNi} \quad \mathrm{NCs}, \quad \mathrm{Ni} @ \mathrm{Ru}_{0.6} \mathrm{Co}_{0.4} \quad \mathrm{NCs}$ and 

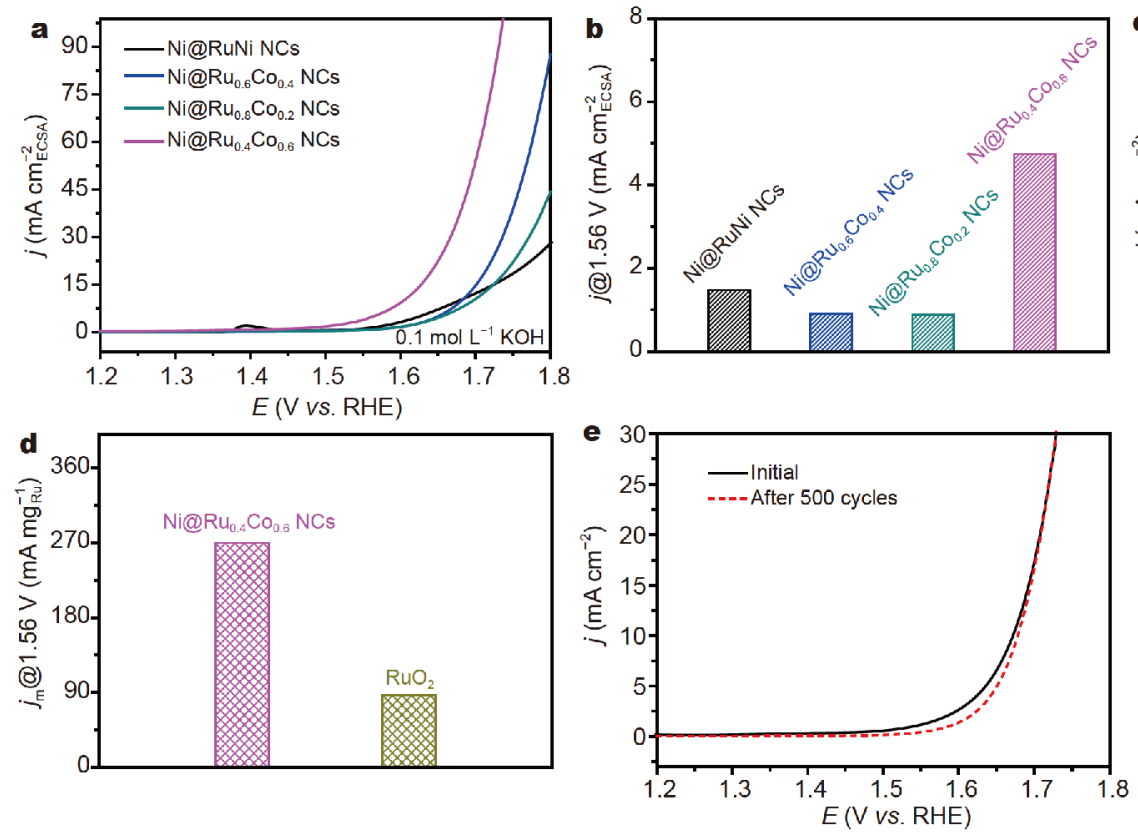
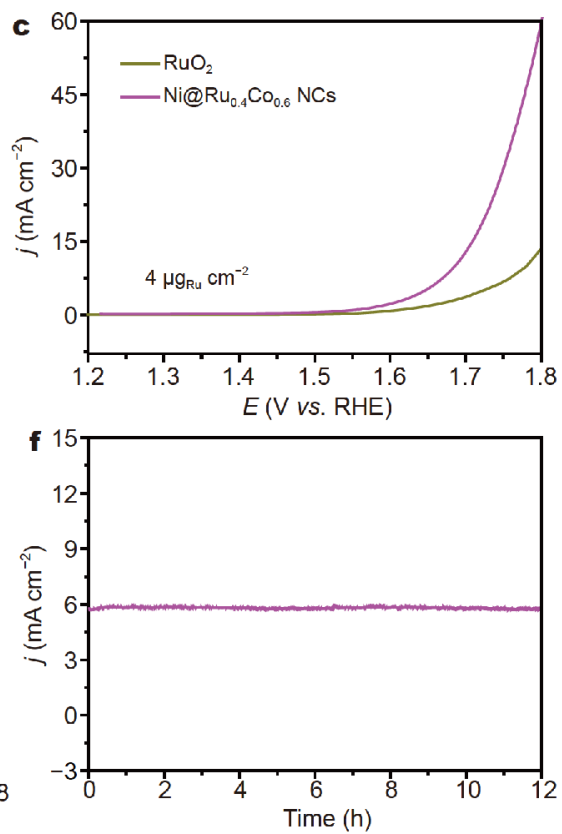

Figure 5 (a) The specific activity for OER normalized by ECSA in $0.1 \mathrm{~mol} \mathrm{~L}^{-1} \mathrm{KOH}$. (b) The current density of various catalysts normalized by ECSA at the overpotential of $330 \mathrm{mV} v$ s. RHE. (c) Polarization curves of $\mathrm{Ni} @ \mathrm{Ru}_{0.4} \mathrm{Co}_{0.6} \mathrm{NCs}$ and commercial $\mathrm{RuO}_{2}$ normalized by geometric area at low loading mass. (d) The corresponding mass activity of $\mathrm{Ni} @ \mathrm{Ru}_{0.4} \mathrm{Co}_{0.6} \mathrm{NCs}$ and commercial $\mathrm{RuO}_{2}$ at the overpotential of $330 \mathrm{mV} v$ s. RHE. (e)

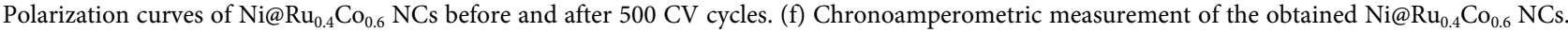

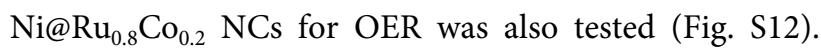
The current density can remain constant with slight fluctuation in the same operating environment. Similarly, the morphologies of the aforementioned catalysts after the OER stability test were characterized by TEM (Fig. S13), and they were able to keep the good dispersibility. Based on the experimental results above, we fabricated an alkaline water electrolyzer using

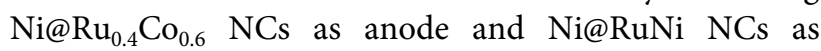
cathode, respectively. Fig. S14a exhibits the polarization curve of water splitting in aqueous $0.1 \mathrm{~mol} \mathrm{~L}^{-1} \mathrm{KOH}$, which can afford a current density of $10 \mathrm{~mA} \mathrm{~cm}^{-2}$ at voltage of $1.69 \mathrm{~V}$. Moreover, the electrolyzer is able to maintain constant current density for more than $15 \mathrm{~h}$ without detectable decline (Fig. S14b), showing its promise for alkaline overall water splitting.

\section{CONCLUSIONS}

To summarize, we demonstrate a facile wet-chemical strategy to prepare a new class of Ni@RuM electrocatalysts for effective HER and OER in alkaline condition. They feature with high $\mathrm{Ru}$ atom utilization and the modulated electronic structure via adjusting thin Ru alloy shell, making them exhibit much enhanced specific and mass activities for HER and OER catalysis. At the over- potential of $70 \mathrm{mV}$ vs. RHE, the core@shell Ni@RuNi NCs show a remarkable HER specific activity of $12 \mathrm{~mA} \mathrm{~cm}_{\mathrm{ECSA}}{ }^{-2}$ and mass activity of $1590 \mathrm{~mA} \mathrm{mg}_{\mathrm{Ru}}{ }^{-1}$ (twice higher than that of the commercial $\mathrm{Pt} / \mathrm{C}$ ). Meanwhile, the mass activity of the core-shell Ni@ $\mathrm{Ru}_{0.4} \mathrm{Co}_{0.6}$ NCs for OER is about $270 \mathrm{~mA} \mathrm{mg}_{\mathrm{Ru}}{ }^{-1}$ at the overpotential of $330 \mathrm{mV} v s$. RHE, almost three times higher than the commercial $\mathrm{RuO}_{2}$. This work highlights the high mass activity of Ru-based electrocatalysts achieved by introducing core@shell nanostructure with regulable shell construction.

Received 22 April 2019; accepted 20 June 2019; published online 19 July 2019

1 Anantharaj S, Ede SR, Sakthikumar K, et al. Recent trends and perspectives in electrochemical water splitting with an emphasis on sulfide, selenide, and phosphide catalysts of $\mathrm{Fe}, \mathrm{Co}$, and $\mathrm{Ni}$ : a review. ACS Catal, 2016, 6: 8069-8097

2 Yan Y, Xia BY, Zhao B, et al. A review on noble-metal-free bifunctional heterogeneous catalysts for overall electrochemical water splitting. J Mater Chem A, 2016, 4: 17587-17603

3 Li C, Hou J, Wu Z, et al. Acid promoted $\mathrm{Ni} / \mathrm{NiO}$ monolithic electrode for overall water splitting in alkaline medium. Sci China Mater, 2017, 60: 918-928

4 Wang J, Cui W, Liu Q, et al. Recent progress in cobalt-based heterogeneous catalysts for electrochemical water splitting. Adv Mater, 2016, 28: 215-230 
5 Gao WK, Yang M, Chi JQ, et al. In situ construction of surface defects of carbon-doped ternary cobalt-nickel-iron phosphide nanocubes for efficient overall water splitting. Sci China Mater, 2019, 341

6 Xiao Y, Tian C, Tian M, et al. Cobalt-vanadium bimetal-based nanoplates for efficient overall water splitting. Sci China Mater, 2017, 61: 80-90

7 Zheng X, Cao Y, Han X, et al. Pt embedded $\mathrm{Ni}_{3} \mathrm{Se}_{2} @ \mathrm{NiOOH}$ coreshell dendrite-like nanoarrays on nickel as bifunctional electrocatalysts for overall water splitting. Sci China Mater, 2019, 62: 1096-1104

8 Mao S, Wen Z, Ci S, et al. Perpendicularly oriented $\mathrm{MoSe}_{2} /$ graphene nanosheets as advanced electrocatalysts for hydrogen evolution. Small, 2015, 11: 414-419

9 Lai F, Yong D, Ning X, et al. Bionanofiber assisted decoration of few-layered $\mathrm{MoSe}_{2}$ nanosheets on 3D conductive networks for efficient hydrogen evolution. Small, 2017, 13: 1602866

10 Zhuang M, Ou X, Dou Y, et al. Polymer-embedded fabrication of $\mathrm{Co}_{2} \mathrm{P}$ nanoparticles encapsulated in N,P-doped graphene for hydrogen generation. Nano Lett, 2016, 16: 4691-4698

11 Zhang C, Huang Y, Yu Y, et al. Sub-1.1 nm ultrathin porous CoP nanosheets with dominant reactive $\{200\}$ facets: a high mass activity and efficient electrocatalyst for the hydrogen evolution reaction. Chem Sci, 2017, 8: 2769-2775

12 Zhao X, Ma X, Sun J, et al. Enhanced catalytic activities of surfactant-assisted exfoliated $\mathrm{WS}_{2}$ nanodots for hydrogen evolution. ACS Nano, 2016, 10: 2159-2166

13 Xu K, Cheng $\mathrm{H}$, Liu L, et al. Promoting active species generation by electrochemical activation in alkaline media for efficient electrocatalytic oxygen evolution in neutral media. Nano Lett, 2017, 17: $578-583$

14 He R, Hua J, Zhang A, et al. Molybdenum disulfide-black phosphorus hybrid nanosheets as a superior catalyst for electrochemical hydrogen evolution. Nano Lett, 2017, 17: 4311-4316

15 Tang T, Jiang WJ, Niu S, et al. Electronic and morphological dual modulation of cobalt carbonate hydroxides by Mn doping toward highly efficient and stable bifunctional electrocatalysts for overall water splitting. J Am Chem Soc, 2017, 139: 8320-8328

16 Gao K, Wang Y, Wang Z, et al. Ru nanodendrites composed of ultrathin fcc/hcp nanoblades for the hydrogen evolution reaction in alkaline solutions. Chem Commun, 2018, 54: 4613-4616

17 Su J, Yang Y, Xia G, et al. Ruthenium-cobalt nanoalloys encapsulated in nitrogen-doped graphene as active electrocatalysts for producing hydrogen in alkaline media. Nat Commun, 2017, 8: 14969

18 Hwang H, Kwon T, Kim HY, et al. Ni@Ru and NiCo@Ru coreshell hexagonal nanosandwiches with a compositionally tunable core and a regioselectively grown shell. Small, 2018, 14: 1702353

19 Zhang C, Liu Y, Chang Y, et al. Component-controlled synthesis of necklace-like hollow $\mathrm{Ni}_{x} \mathrm{Ru}_{y}$ nanoalloys as electrocatalysts for hydrogen evolution reaction. ACS Appl Mater Interfaces, 2017, 9: 17326-17336

20 Kong X, Xu K, Zhang C, et al. Free-standing two-dimensional Ru nanosheets with high activity toward water splitting. ACS Catal, 2016, 6: 1487-1492

21 Wang L, Saveleva VA, Zafeiratos S, et al. Highly active anode electrocatalysts derived from electrochemical leaching of $\mathrm{Ru}$ from metallic $\mathrm{Ir}_{0.7} \mathrm{Ru}_{0.3}$ for proton exchange membrane electrolyzers. Nano Energy, 2017, 34: 385-391

$22 \mathrm{Li}$ G, Li S, Ge J, et al. Discontinuously covered $\mathrm{IrO}_{2}-\mathrm{RuO}_{2} @ \mathrm{Ru}$ electrocatalysts for the oxygen evolution reaction: how high activity and long-term durability can be simultaneously realized in the synergistic and hybrid nano-structure. J Mater Chem A, 2017, 5: $17221-17229$

23 Bhowmik T, Kundu MK, Barman S. Growth of one-dimensional $\mathrm{RuO}_{2}$ nanowires on g-carbon nitride: an active and stable bifunctional electrocatalyst for hydrogen and oxygen evolution reactions at all $\mathrm{pH}$ values. ACS Appl Mater Interfaces, 2016, 8: 28678-28688

24 Ye R, Liu Y, Peng Z, et al. High performance electrocatalytic reaction of hydrogen and oxygen on ruthenium nanoclusters. ACS Appl Mater Interfaces, 2017, 9: 3785-3791

25 Strasser P, Koh S, Anniyev T, et al. Lattice-strain control of the activity in dealloyed core-shell fuel cell catalysts. Nat Chem, 2010, 2: $454-460$

26 Sneed BT, Young AP, Jalalpoor D, et al. Shaped Pd-Ni-Pt coresandwich-shell nanoparticles: influence of $\mathrm{Ni}$ sandwich layers on catalytic electrooxidations. ACS Nano, 2014, 8: 7239-7250

27 Chen Z, Zhang X, Lu G. Multiscale computational design of core/ shell nanoparticles for oxygen reduction reaction. J Phys Chem C, 2017, 121: 1964-1973

28 Oezaslan M, Hasché F, Strasser P. Pt-based core-shell catalyst architectures for oxygen fuel cell electrodes. J Phys Chem Lett, 2013, 4: 3273-3291

29 Yang L, Vukmirovic MB, Su D, et al. Tuning the catalytic activity of Ru@Pt core-shell nanoparticles for the oxygen reduction reaction by varying the shell thickness. J Phys Chem C, 2013, 117: 1748-1753

30 Wang $\mathrm{X}, \mathrm{Su} \mathrm{R}$, Aslan $\mathrm{H}$, et al. Tweaking the composition of NiMoZn alloy electrocatalyst for enhanced hydrogen evolution reaction performance. Nano Energy, 2015, 12: 9-18

31 Wang D, Xin HL, Hovden R, et al. Structurally ordered intermetallic platinum-cobalt core-shell nanoparticles with enhanced activity and stability as oxygen reduction electrocatalysts. Nat Mater, 2013, 12: 81-87

32 Wang JX, Inada $\mathrm{H}, \mathrm{Wu} \mathrm{L}$, et al. Oxygen reduction on well-defined core-shell nanocatalysts: particle size, facet, and Pt shell thickness effects. J Am Chem Soc, 2009, 131: 17298-17302

33 Choi SI, Shao M, Lu N, et al. Synthesis and characterization of Pd@Pt-Ni core-shell octahedra with high activity toward oxygen reduction. ACS Nano, 2014, 8: 10363-10371

34 Feng Q, Zhao S, He D, et al. Strain engineering to enhance the electrooxidation performance of atomic-layer Pt on intermetallic $\mathrm{Pt}_{3} \mathrm{Ga}$. J Am Chem Soc, 2018, 140: 2773-2776

35 Gu J, Guo Y, Jiang YY, et al. Robust phase control through heteroseeded epitaxial growth for face-centered cubic Pt@Ru nanotetrahedrons with superior hydrogen electro-oxidation activity. J Phys Chem C, 2015, 119: 17697-17706

36 Liu D, Xie M, Wang C, et al. Pd-Ag alloy hollow nanostructures with interatomic charge polarization for enhanced electrocatalytic formic acid oxidation. Nano Res, 2016, 9: 1590-1599

37 Shan J, Ling T, Davey K, et al. Transition-metal-doped RuIr bifunctional nanocrystals for overall water splitting in acidic environments. Adv Mater, 2019, 31: 1900510

38 Menezes PW, Panda C, Garai S, et al. Structurally ordered intermetallic cobalt stannide nanocrystals for high-performance electrocatalytic overall water-splitting. Angew Chem Int Ed, 2018, 57: 15237-15242

39 Yang TT, Zhu H, Wan M, et al. Highly efficient and durable PtCo alloy nanoparticles encapsulated in carbon nanofibers for electrochemical hydrogen generation. Chem Commun, 2016, 52: 990-993 
Acknowledgements This work received funding from the National Natural Science Foundation of China (21427811, 21721003 and 51671003), the Ministry of Science and Technology, China (2016YFA0203200), the Youth Innovation Promotion Association CAS (2016208) and Jilin Province Science Technology Development Plan Project (20170101194JC).

Author contributions Zhang S and Lv F designed and conducted the experiments to prepare samples and electrochemical tests. The samples were characterized with support from Zhu $\mathrm{H}$ and Xing H. All authors contributed to the general discussion.

Conflict of interest The authors declare that they have no conflict of interest.

Supplementary information Supplementary materials are available in the online version of the paper.

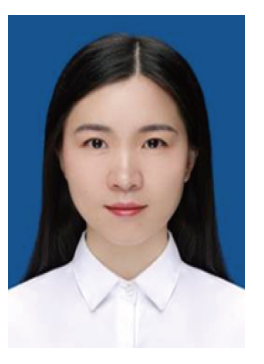

Shan Zhang is currently a $\mathrm{PhD}$ student in Changchun Institute of Applied Chemistry, Chinese Academy of Sciences under the supervision of Prof. Erkang Wang. Her current interest focuses on the fabrication of nanomaterial for electrocatalysis.

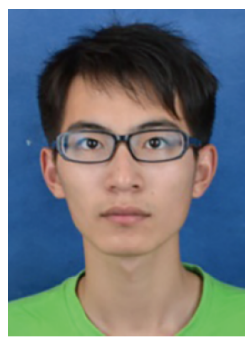

Fan Lv is currently a $\mathrm{PhD}$ student in the Department of Materials Science and Engineering at Peking University under the supervision of Prof. Shaojun Guo. His current research interest focuses on the development of nanostructured advanced energy materials for electrocatalysis and alkali ion batteries.

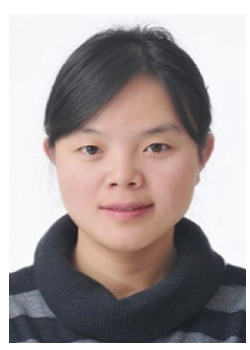

Jing Li received her $\mathrm{PhD}$ degree from Changchun Institute of Applied Chemistry under the direction of Prof. Erkang Wang in 2009. In 2010, she joined Changchun Institute of Applied Chemistry. In 2013, she was promoted as an Associate Professor. Her scientific interests focus on the functionalized nanoprobes for chemiluminescence, eletrocatalysis, electroanalysis and the fabrication of bipolar electrochemistry.

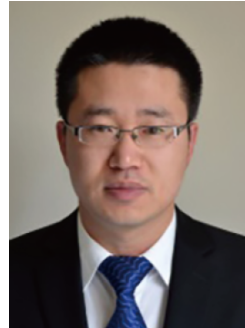

Shaojun Guo is currently a professor of materials science and engineering with a joint appointment at the Department of Energy \& Resources Engineering at the College of Engineering, Peking University. He received his BSc in chemistry from Jilin University (2005), $\mathrm{PhD}$, in analytical chemistry from the Chinese Academy of Sciences (2010), worked as a postdoctoral research associate from Jan. 2011 to Jun. 2013 at Brown University and earned the very prestigious position of J. Robert Oppenheimer Distinguished Fellow at Los Alamos National Laboratory. In 2014-2017, he was selected by Thomson Reuters into their prestigious list of the world's most Highly Cited Researchers. His research interests are in engineering nanocrystals and 2D materials for catalysis, renewable energy, sensors, and therapy.

\section{高质量活性的Ni@RuM ( M=Ni or Co)核壳@纳米 晶用于催化水分解}

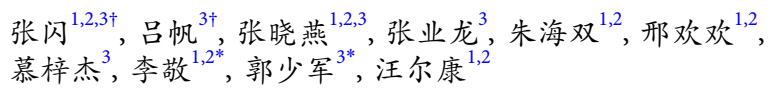

摘要 发展一种高质量活性的高效水分解催化剂对于实现大规模 制氢来说至关重要, 但目前这仍是一个巨大的挑战. 我们报道了简 便的一锅法来合成一系列核@壳Ni@RuM ( M=Ni or $\mathrm{Co})$ 纳米晶 $(\mathrm{NCs})$, 并将其用于高效催化水分解, 该系列催化剂均以金属 $\mathrm{Ni}$ 为 核, 壳层则是组分可调控的RuM ( $\mathrm{M}=\mathrm{Ni}$ or $\mathrm{Co})$ 合金. 在这些催化 剂中, Ni@RuNi NCs对催化产氢表现出优异的性能, 在过电位为 $0.7 \mathrm{~V}$ (vs. RHE)时, 其质量活性高达 $1590 \mathrm{~mA} \mathrm{mg}_{\mathrm{Ru}}{ }^{-1}$, 是同等条件下 商业 $\mathrm{Pt} / \mathrm{C}$ 的 1.7 倍 $\left(950 \mathrm{~mA} \mathrm{mg}_{\mathrm{Pt}}{ }^{-1}\right)$. 而对于产氧反应来说, 质量活性 最高的则是 $\mathrm{Ni} @ \mathrm{Ru}_{0.4} \mathrm{Co}_{0.6} \mathrm{NCs}$, 在电位为 $1.56 \mathrm{~V} v s$. RHE时, 其质量 活性达 $270 \mathrm{~mA} \mathrm{mg}_{\mathrm{Ru}}{ }^{-1}$, 远远超过了商业 $\mathrm{RuO}_{2}\left(89 \mathrm{~mA} \mathrm{mg}_{\mathrm{Ru}}{ }^{-1}\right)$. 这些 催化剂优异的质量活性归因于它们的核@壳结构, 壳层中金属Ru通 过与金属 $\mathrm{Ni}$ 或者Co形成合金来调控自身的电子结构, 使其更有利 于产氢/氧反应的进行. 